\title{
LA AGENDA DE INVESTIGACIÓN DEL TURISMO MEDIANTE EL ANÁLISIS CUANTITATIVO DE REDES SOCIALES (QSNA)
}

\author{
Rafael Merinero Rodríguez. \\ Universidad Pablo de Olavide. Sevilla
}

\section{RESUMEN}

El trabajo realiza un recorrido por la literatura aparecida en los últimos años en las revistas científicas y libros que han utilizado el Análisis Cuantitativo de Redes Sociales (QSNA, en inglés) para el estudio del turismo. Se presenta de forma sistemática todas las aportaciones científicas que han usado los métodos y técnicas propias del QSNA para el análisis del turismo, lo que permitirá que cualquier investigador pueda disponer de las referencias oportunas con el objeto de poder orientar sus trabajos de investigación utilizando el QSNA. A partir del análisis de todas estas aportaciones se plantea una propuesta de avance para la futura agenda de investigación del turismo desde el QSNA.

Palabras clave: Redes de actores turísticos; Agenda de investigación en turismo; Análisis Cuantitativo de Redes Sociales.

\section{Research agenda for tourism using Quantitative Social Network Analysis (QSNA)}

\section{ABSTRACT}

This work, we examine the literature that has appeared in recent years, in the international scientific journals and books, which has used the Quantitative Social Networks Analysis (QSNA) to study the phenomenon of tourism. In this sense, the interest of this work is that we present in a systematic and orderly way, all the scientific contributions that have used the methods and techniques of the QSNA for tourism analysis; and that make their current

Recibido: 17 de mayo de 2014

Devuelto para su revisión: 26 de septiembre de 2014

Aceptado: 10 de octubre de 2014

Centro de Sociología y Políticas Locales. Universidad Pablo de Olavide. Carretera de Utrera Km 1. 41013 SEVILLA (España). E-mail: rmerrod@upo.es 
research calendar. Therefore, this effort to systematize the research appeared about the topic; allow that any researcher could have appropriate references, to guide their research using the QSNA. But at the same time, we present a proposal to improve the future tourism research agenda, based on the QSNA, so that future researches can provide a framework in which to raise their works and analysis.

Keywords: Networks of tourism actors; Tourism Research Agenda; Quantitative Analysis of Social Networks.

\section{INTRODUCCIÓN}

El interés por incorporar el uso del concepto de red para la comprensión del turismo ha sido un elemento de gran importancia en la literatura científica reciente (Cohen y Cohen, 2012). Por tanto, podemos destacar que el fenómeno turístico ha sido un ámbito de análisis que no ha estado ajeno al desarrollo de la perspectiva de las redes sociales como instrumento analítico en las Ciencias Sociales en general (Watts, 2003).

Sin embargo, es importante poner de manifiesto que tanto para las Ciencias Sociales en general como para el estudio del turismo en particular no existe un único concepto de red, sino que han sido múltiples y variados los enfoques que se han venido utilizando (Scott, 2000; Requena, 2003; Scott, Cooper y Baggio, 2007), lo que nos lleva a mantener que existe una perspectiva de redes que está integrada por diferentes propuestas teóricas y metodológicas. Aunque también es cierto que todas ellas comparten una misma aproximación conceptual para abordar la explicación de los fenómenos que se pretender estudiar: un determinado fenómeno social es susceptible de ser concebido como un conjunto de partes claramente diferenciadas que se interrelacionan entre ellas.

Desde esta perspectiva, está más que justificado el interés por abordar la comprensión del turismo desde las redes: por un lado, el turismo como actividad productiva está claramente fragmentado en un conjunto de partes que constituyen los diferentes componentes de una experiencia turística (viaje, alojamiento, restauración, seguridad, recursos de interés para la visita, etc., los cuales dependen de la acción de diferentes entidades y organizaciones); y por otro lado, para ser consumido o usado por el turista se requiere un cierto grado de interacción de dichos componentes, lo que irremediablemente implica diferentes formas de acción colectiva.

Sin ánimo de ser exhaustivos, sino más bien descriptivos, podemos mantener que existen cuatro formas claramente diferenciadas de aplicar la perspectiva de redes al estudio del turismo: la red como una metáfora de las interrelaciones entre los diferentes componentes del producto o el destino turístico; los factores que influyen y condicionan positiva o negativamente la existencia de interacciones; la red como contenido en el que se sustentan las relaciones entre las diferentes partes del hecho turístico analizado; y en cuarto lugar, encontraríamos el interés por los componentes de la estructura de la red.

Pero desde el punto de vista metodológico estas cuatro diferentes formas de abordar el estudio del turismo se han concretado en dos enfoques fundamentales: el enfoque cualitativo y el enfoque cuantitativo (Scott, Baggio y Cooper, 2008). En el primero de los 
enfoques el análisis de las relaciones se sustenta en las propiedades de contenido de las relaciones que se concretan en la existencia de interrelaciones entre los diferentes componentes de la actividad turística (generalmente identificados estos como actores turísticos) expresadas en términos de los factores que condicionan o posibilitan las relaciones, su tipología (formal/informal), su forma (colaboración/cooperación) su concreción más o menos institucionalizada, etc. Y en el segundo de los enfoques, se trata de abordar las propiedades reticulares de las redes que se derivan de la aplicación de técnicas matemáticas complejas que aportan la configuración estructural de las relaciones.

En este trabajo nos vamos a concentrar en este segundo enfoque, de manera que a través de la adopción de principios de la matemática de matrices se pueden obtener características de las redes de relación para abordar el análisis del fenómeno del turismo. Se trata de aplicar el marco teórico-metodológico denominado como Análisis de Redes Sociales que se ha venido conformando en los últimos años en las Ciencias Sociales al estudio y comprensión del turismo. Dicho marco se sustenta en la aplicación de principios matemáticos al estudio de las interrelaciones para abordar explicaciones de fenómenos sociales complejos, que ha venido siendo aplicado a la investigación en las diferentes Ciencias Sociales (Requena, 2003), y que ha cobrado una especial relevancia analítica en los dos últimas décadas. Son muchos y variados los campos de las diferentes Ciencias Sociales a las que se ha venido aplicando el Análisis de Redes Sociales: sanidad, políticas públicas, desarrollo económico, organización empresarial, etc. (Molina, 2001). El objetivo fundamental del Análisis de Redes Sociales está en estudiar las propiedades estructurales de las redes, entendidas estas como un conjunto de nodos (elementos) y los vínculos que se producen entre estos -relaciones- (Wasserman y Galasklewicz, 1994). Se trata, por tanto, de poner el centro de interés analítico en las propiedades reticulares de la red, más que en las características individuales de los elementos que harían posibles las relaciones que sustentan la red. Así, queda claro que la unidad de análisis es la red y sus propiedades y no las características atributivas de los elementos que conforman la red (Maden y Lin, 1982). No es este el momento ni el lugar para establecer un debate en profundidad sobre las características y los principios teóricos-metodólogicos que inspiran este enfoque, ya que existe una importante y dilatada literatura científica sobre el Análisis de Redes Sociales (Burt y Minor, 1983; Knoke y Kuklinski, 1982; Scott, 1991; Wellman y Berkowitz, 1988) a la que podemos recurrir en cualquier momento para una mayor comprensión del enfoque aquí propuesto.

Pero si es conveniente precisar que desde este enfoque la red se conforma como un conjunto de elementos (personas, grupos, organizaciones, países o acontecimientos) a los que se le denominan nodos y los vínculos específicos que se producen entre ellos a los que denominamos lazos. Se trata de a partir de diferentes técnicas de obtención de información conseguir datos relacionales entre los elementos que conforman la red para aplicar sobre ellos análisis sustentados en álgebra matricial y en operaciones de grafos que nos proporcionarán las propiedades estructurales de la red estudiada, a partir de las medidas de cohesión (centralidad y agrupación) y de equivalencia estructural.

El objetivo de este trabajo consiste en realizar un recorrido por la literatura aparecida en los últimos años en las principales revistas científicas nacionales e internacionales y en otras publicaciones, espacialmente libros y capítulos de libros, que ha utilizado el Aná- 
lisis Cuantitativo de Redes Sociales (QSNA) para el estudio del fenómeno del turismo. En este sentido, el interés de este trabajo está en que se presenta de forma sistemática y ordenada todas las aportaciones científicas que han usado los métodos y técnicas propias del QSNA para el análisis del turismo y que conforman su actual agenda de investigación. Por lo tanto, este esfuerzo de sistematización de la investigación aparecida sobre la materia permitirá que cualquier investigador pueda disponer de las referencias oportunas con el objeto de poder orientar sus trabajos de investigación utilizando el QSNA. Pero al mismo tiempo, presentaremos una propuesta de avance para la futura agenda de investigación del turismo desde el QSNA, de manera que futuras investigaciones puedan disponer de un marco de referencia en la que plantear los trabajos y análisis.

\section{EL QSNA EN EL MARCO DE LA PERSPECTIVA DE REDES PARA EL ESTU- DIO DEL TURISMO}

Como hemos destacado anteriormente, no existe un único enfoque teórico-metodológico de redes en las Ciencias Sociales en general ni para el estudio del turismo en particular, sino que por el contrario, existe una multitud de enfoques de redes, lo que nos lleva a hablar más de una «perspectiva relacional» para el estudio del turismo configurada por una amplitud de propuestas analíticas, en la que el QSNA sería una más, tal y como se puede comprobar en la tabla siguiente que recoge los diferentes enfoques existentes.

La primera idea que se deriva es que el QSNA como línea de investigación forma parte de un campo científico más amplio al que podemos denominar como «perspectiva relacional» que está caracterizado por la utilización de la idea de relaciones -y por extensión del concepto de red- como un elemento de gran importancia para la comprensión y el conocimiento del fenómeno turístico. No es este el momento ni el lugar de hacer una exposición pormenorizada de dichas líneas de investigación, pero en la tabla anterior podemos encontrar una breve exposición de las seis líneas de investigación que forman parte de la denominada «perspectiva relacional» de la investigación en turismo: Ciencias Sociales; Community Approach; Sistema Turístico; Teoría de los Stakholders; Clusters Turístico y QSNA).

A partir de esta información podemos destacar dos ideas fundamentales: la primera de ellas, es que podemos mantener que la utilización de las relaciones como elemento explicativo del turismo ha tenido una amplia e importante utilización en la investigación existente en la literatura científica. Y la segunda de ellas - que desarrollaremos a continuación- es que los trabajos encontrados en dicha literatura científica que aplican el QSNA para el estudio del fenómeno turístico han sido bastante escasos; en concreto en los últimos 25 años apenas han aparecido en torno a 40 trabajos en los que se aplique esta línea de investigación.

A continuación vamos a detallar todos estos trabajos que hemos encontrado en la literatura científica. Por lo tanto en este trabajo no realizaremos una propuesta de explicación metodológica de cómo llevar a cabo una investigación aplicando el QSNA al estudio del turismo, para ello podemos destacar que existen algunos trabajos que si se centran en este asunto ${ }^{1}$.

1 La explicación de la aplicación de métodos y técnicas propias del QSNA al turismo en toda su extensión la podemos encontrar en Scott, Baggio y Cooper (2008a) y Merinero (2012). 


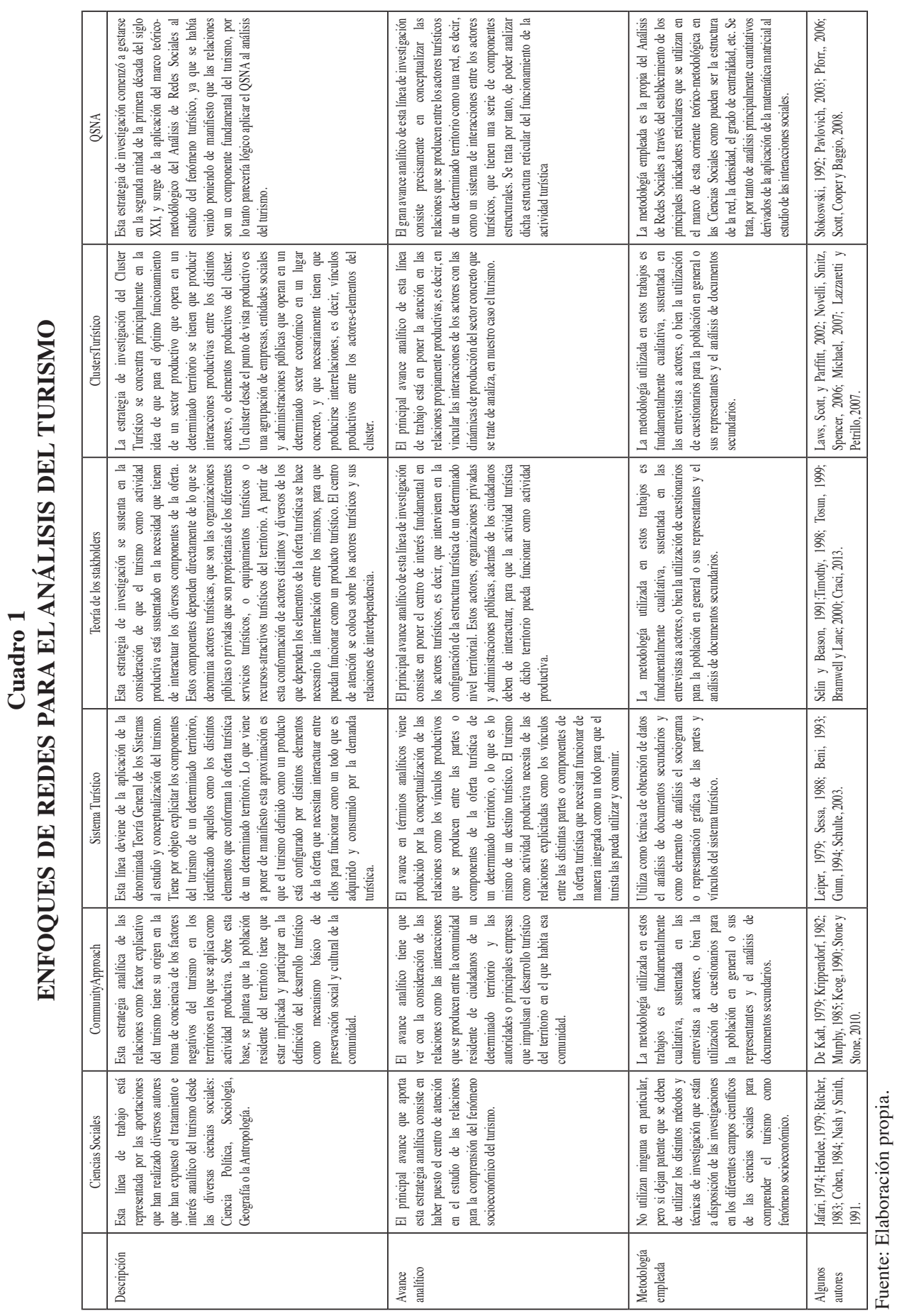

Cuadernos de Turismo, 36, (2015), 269-294 


\section{LA LITERATURA CIENTÍFICA DEL QSNA APLICADA AL TURISMO}

En este apartado vamos a realizar una descripción de la literatura científica que ha aparecido en las revistas científicas a nivel nacional e internacional y en algunas publicaciones especializadas en turismo en la que se ha utilizado el QSNA para el estudio del fenómeno turístico. El primer trabajo que encontramos en la literatura científica que utiliza la aplicación del QSNA para el estudio del turismo es realizado por Marcia Cobb en cuatro pequeñas comunidades del estado de Michigan en Estados Unidos. En este trabajo se pone de manifiesto que la centralidad de los actores empresariales en las redes locales de actores es fundamental para tener influencia en las decisiones sobre la planificación turística de las comunidades (Cobb, 1990). El principal avance analítico que aporta este trabajo está en establecer como las estructuras de poder de las redes de actores es clave para conformar la toma de decisiones en materia de la planificación turística de un determinado territorio. La unidad de análisis que se utiliza en este trabajo está conformada por el plan turístico de las comunidades objeto de estudio, donde los elementos de contenido de dicho análisis tienen que ver con las características reticulares (en este caso la centralidad de los actores) y las dimensiones del análisis son lo vínculos que en términos de proceso productivo del turismo de un determinado territorio se producen, en este caso concreto las características de las relaciones para producir un plan de actuación turístico de un determinado territorio; en cuanto al alcance del trabajo es el del estudio comparado de un número pequeño de casos; en cuanto al objetivo analítico del trabajo es explicativo, exponiendo como las características de las relaciones influyen en la configuración de un plan turístico; y en lo que respecta a la metodología, el trabajo utiliza por primera vez medias de centralidad de actores.

De principio de los noventa son también dos trabajos desarrollados por Patricia Stokowski en los que aplica el QSNA al estudio del turismo. En el primero de ellos aplica la teoría de los lazos débiles para explicar las diferencias que existen en referencia al uso de las personas de sus redes personales para organizar las vacaciones en Texas, de manera que pone de manifiesto que lazos fuertes (establecidos por una persona con sus amigos) son utilizados para obtener información sobre potenciales destinos turísticos; mientras que los lazos débiles (contactos con conocidos) son usados aspectos organizativos de la visita como necesidades del viaje, aspectos de seguridad, etc (Stokowski, 1990). En el segundo de los trabajos analizan como las estructuras de socialización influyen en las redes de relación interpersonales para la organización de los viajes, de manera que las mujeres usan las redes familiares para organizar los viajes, mientras que los hombres utilizan redes extra-familiares para dicha organización (Stokowski y Lee, 1991). El principal avance analítico que aportan estos dos trabajos está precisamente en demostrar que las redes interpersonales ejercen una influencia determinante sobre la organización de ciertas actividades relacionadas con la actividad turística, especialmente con las características organizativas de los viajes de vacaciones. La unidad de análisis utilizada en estos trabajos se centra claramente en las personas, y en concreto como desarrollan estas los aspectos organizativos de la actividad turística, concretamente en la conformación de cuestiones relacionadas con la toma de decisiones personales en referencia a la organización de las vacaciones y los viajes; en cuanto a los elementos de contenido de las relaciones clara- 
mente se centran en las características de las reticulares de las relaciones, centrando sus estudios en dimensiones relacionadas con la organización productiva del turismo, es decir, con la toma de decisiones sobre la organización de los viajes; en cuanto al alcance de los estudios, son claramente resultado de estudios de caso; en cuanto a su objetivo de análisis persiguen poner de manifiesto cómo las redes tienen una influencia sobre la actividad turística, en este caso sobre la organización del viaje.

Hasta doce años después de los trabajos de Stokowski no encontramos de nuevo una referencia al uso del QSNA para estudiar el fenómeno del turismo -o algunos aspectos particulares de él- aunque es cierto que dicha aportación no se centra tanto en la aplicación del QSNA sino en reclamar dicha aplicación para la comprensión del turismo, y es la realizada por John Urry quién en un trabajo expone la importancia que tienen los contactos cara a cara entre las personas a la hora de recomendar y proponer visitas turísticas a determinados destinos, y la importancia tan especial que debería tener la aplicación de técnicas de análisis estructural de estas redes personales cara a cara para mejorar el conocimiento que sobre las mismas se tiene (Urry, 2003). A pesar de que este es un aspecto contrastado y demostrado la literatura científica sobre el turismo le ha prestado un escaso interés, y se hace más que necesario, según el autor, impulsar análisis en esta dirección.

Con la misma diferencia temporal respecto a los trabajos de aplicación del QSNA al turismo de principios de los años noventa (doce años más tarde), encontramos en 2003 uno de los trabajos que han aportado un avance científico considerable en relación a la aplicación del análisis reticular al estudio y comprensión del turismo. Se trata de la investigación realizada por Kathryn Pavolvich sobre el destino turístico de «Waitomo Caves» (Pavlovich, 2003), en el que el avance analítico viene producido porque se estudia por primera vez cómo las propiedades estructurales de las redes tienen una incidencia en las posibilidades de desarrollo del destino. Así, el trabajo de investigación pone de manifiesto como las características reticulares de la rede de actores turísticos del destino está directamente relacionada con el desarrollo turístico, de manera que, a medida que la red de actores va creciendo en un mayor número de actores centrales y las relaciones presentan una mayor densidad los resultados turísticos del territorio de «Waitomo Caves» mejora en términos de una mayor capacidad de atracción de turistas al destino. La línea de avance propuesta en este trabajo parte de la utilización de la unidad de análisis que es el destino, es decir, los componentes de la oferta turística de un determinado territorio, o lo que es lo mismo, las organizaciones, las empresas y las personas físicas que operan en la actividad turística de un determinado lugar. En lo que respecta a los elementos de contenido de las redes, este trabajo es el primero que se concentra en las características reticulares de las mismas; y estas propiedades las aplica para conocer los vínculos efectivos que se dan entre los diferentes componentes de la oferta territorial de cara a producir actividad turística para el destino; dicho análisis lo aplica a un solo caso de estudio y tiene por objetivo fundamental comprobar si las características de las relaciones turísticas tienen una incidencia en los resultados en términos de desarrollo turístico del territorio. Para ello, aplica los métodos y técnicas propios del QSNA como son la identificación de la matriz de relaciones entre los actores y el cálculo de indicadores reticulares como son la densidad y la centralidad de la red. 
Otro trabajo en la línea del anterior es el que realizó Samantha Jones en el año 2005 relativo al estudio del uso del capital social como elemento en el que sustentar el desarrollo de un proyecto de ecoturismo en una aldea de Gambia. Aunque este trabajo se concentra más en el debate en torno al concepto de capital social y sus dimensiones cognitivas y estructurales, utiliza recursos analíticos del QSNA. Jones pone de manifiesto que el capital social existente en la aldea analizada ha posibilitado la conformación y desarrollo de un proyecto de ecoturismo en el territorio, que ha sido el resultado de la existencia de una alta implicación de las organizaciones formales y las instituciones de la aldea para trabajar colaborativamente en pos de dicho proyecto, y que dicha cooperación ha dado como resultado que otras instituciones y organizaciones de fuera de la aldea hayan aportado recursos para la ejecución de este proyecto; plantea, una vinculación directa entre las interacciones entre los actores de la aldea y la consecución del objetivo de promover un proyecto ecoturístico (Jones, 2005). Su unidad de análisis sería un proyecto turístico concreto en un determinado territorio; como hemos puesto de manifiesto con anterioridad, el trabajo no está centrado propiamente en el ámbito del QSNA y por tanto, al analizar la existencia de capital social en la comunidad se está centrando en los factores que hacen posible la colaboración, sin embargo, esta autora utiliza algunas propiedades reticulares de la red de actores de la aldea para conformar la dimensión estructural de capital social: expone la red de actores de la aldea en la que representa a estos actores a través de círculos mostrando de este modo los actores centrales de dicha red y la existencia de vínculos entre ellos. En cuanto al alcance del trabajo de investigación se sitúa claramente en la fórmula del estudio de un caso; respecto al objetivo analítico la investigación pretende poner de manifiesto el vínculo que existe entre las relaciones conceptualizadas como capital social más que como componentes reticulares, y los resultados turísticos, en este caso las características del capital social extenso produce el éxito del desarrollo del proyecto de ecoturismo en la aldea. Respecto a la metodología, se ha dicho con anterioridad que aplica el enfoque y las técnicas típicas de los estudios de capital social, pero extraordinariamente utiliza la técnica del mapeo institucional para obtener una representación gráfica de la estructura de la red en cuento a su forma, la ubicación y los vínculos de los actores. Sin embargo, de la aplicación de esta técnica propia del QSNA no se obtienen en el trabajo importantes conclusiones en términos explicativos de los componentes estructurales de la red, sino que más bien se utiliza para evidenciar la forma de dicha red nada más. Por tanto, como ya se ha puesto de manifiesto con anterioridad el impacto de este trabajo en términos de avance analítico del uso del QSNA es muy relativo, ya que si bien pone de manifiesto que las características de las relaciones influyen en el desarrollo del turismo de un determinado territorio, no utiliza las evidencias en términos e características reticulares de la red para ponerlas en relación directa con dichos resultados turísticos.

Otro trabajo realizado en el marco de la aplicación del QSNA al estudio del fenómeno turístico es el que hizo Christof Pforr en 2006 para analizar la configuración estructural de la red de actores que participaron en la configuración de un asunto de política turística en el norte de Australia. Concretamente estudió la red de actores turísticos y sus propiedades reticulares en la conformación del Plan de Desarrollo Turístico del «Northern Territory» de Australia. A través de la aplicación de técnicas de QSNA este autor analiza la configuración de la red de actores que participan en la elaboración del un plan turístico para 
un determinado territorio, centrándose en destacar que actores de los implicados en dicho proceso de toma de decisiones políticas son los más importantes en términos de obtener una posición más central en la red de actores turísticos (Pforr, 2006). El principal, avance analítico que propone este trabajo es precisamente la temática, ya que es la primera vez que mediante la aplicación de instrumentos analíticos se estudia una red de política pública de turismo. En este sentido podemos destacar que la unidad de análisis empleada en el trabajo es la política turística; los elementos de contenido son claramente propiedades reticulares de las relaciones entre los actores implicados en la conformación de dicha política; de esta forma comprobamos que las dimensiones del análisis están conformadas por los vínculos que se producen entre los actores de la red; el alcance del estudio es limitado, ya que ni siquiera se estudia todos los elementos de una política turística de un determinado nivel de administración, sino la configuración de la constelación de actores turísticos en un asunto político concreto, en esta ocasión la definición de un plan de desarrollo turístico impulsado por una administración pública. En cuanto el objetivo de análisis es puramente descriptivo, ya que en el trabajo se pone de manifiesto cuales son los actores más importantes en términos de centralidad y capacidad de acción e influencia de la red de actores turísticos, pero no se destaca la interrelación que existe entre estas propiedades reticulares de la red y algún tipo de resultado turístico, como podría ser por ejemplo el contenido o las orientaciones del plan turístico que hubieras sido resultado de las posiciones dominantes de determinados actores turísticos en la red de Política turística. Quizás lo mas llamativo está en la aplicación de la metodología de análisis que emplea, en concreto para determinar los vínculos entre los actores que los establece en base a tres aspectos fundamentales: reputación de los actores, cooperación entre ellos e intercambio de información: sobre la base de estas tres variables se construye el peso y la centralidad que cada actor tiene en la red, por tanto lo más significativo tiene que ver con la obtención del dato relacional entre los actores.

Hsin-Yu Shih es otro autor que realiza una interesante aportación desde la aplicación del QSNA al estudio del fenómenos del turismo, en su caso en el año 2006 realiza un trabajo de investigación donde analiza el destino turístico de Nantou en Taiwan desde la perspectiva reticular. Su aportación es novedosa en el sentido de que estudio cómo se produce el flujo de entre los dieciséis puntos de visita del destino para observar cómo es la dinámica de desplazamiento de los turistas entre dichos puntos de interés (Shih, 2006). El avance analítico más destacado viene a través del enfoque que adopta su trabajo, ya que los turistas en un determinado territorio se desplazan desde un punto de interés a otro conformando un cierto sentido del itinerario. Por supuesto no todos los puntos turísticos tienen el mismo interés para los visitantes y aplicando el QSNA analiza cómo es el flujo de interrelación del desplazamiento de los visitantes entre los puntos de interés turístico, identificando cuales son los principales puntos interconectados de la ruta real que realizan los turistas, desde qué puntos se accede a otros, y cuales los son los que están marginados. Su unidad de análisis es el destino, pero no analiza los actores que sustentas los elementos de producto del mismo, sino que estudia sólo algunos componentes de dicho destino, en su caso los recursos y puntos de interés visitables. Los elementos de contenido de las relaciones son claramente las características reticulares de las interacciones que se producen entre los componentes analizados, por lo tanto sus dimensiones de análisis están constituidas 
por los vínculos establecidos entre dichos componentes; el alcance de la investigación es un estudio de caso y el objetivo fundamental del trabajo consiste en poner de manifiesto la existencia de relaciones en la actividad turística en el territorio. Las técnicas que utiliza son las propias del QSNA especialmente analiza la centralidad de los elementos turísticos a los que presta atención analítica.

Pero es a raíz de la aparición de la línea de trabajo emprendida por Noel Scott, Rodolfo Baggio y Chris Cooper en 2007 cuando se produce un significativo impulso al desarrollo de trabajos de investigación sobre el turismo aplicando métodos y técnicas del QSNA, ya que estos autores han tenido una intensa producción científica sobre este tema entre 2007 y 2010. De esta manera en el año 2007 aparece un primer trabajo de estos tres autores en el que realizan una descripción de diferentes aportaciones científicas que han usado el análisis de redes en la investigación sobre turismo (Scott, Cooper, y Baggio, 2007). En esta primera aproximación ponen de manifiesto el interés que sobre la perspectiva de las redes sociales y su aplicación al análisis del turismo se está produciendo en la literatura científica; aunque es cierto que en esta primer trabajo se centran principalmente en abordar una perspectiva amplia del análisis de redes tal y cómo ha sido destacado al principio de este trabajo, y sólo aparecen un pequeño número de referencias a trabajos de aplicación exclusiva del QSNA al turismo. Pero lo realmente importante que aporta el trabajo mencionado es que en las tendencias de una futura agenda de investigación en turismo a través del uso del análisis de redes estos autores destacan la aplicación de los métodos y técnicas del QSNA al estudio de los diferentes componentes y dimensiones de los destinos turísticos.

En otro de los trabajos, en este caso el realizado por Rodolfo Baggio el destino turístico de Elba, el autor aplica el QSNA para analizar la realidad turística de dicho destino comprobando las características estructurales de la red de actores turísticos del mismo (Baggio, 2007). El autor se concentra en el concepto de destino turístico y examina las interacciones que se producen entre los operadores turísticos del mismo para poner de manifiesto el grado de cooperación y colaboración existente en el mismo. La unidad de análisis del estudio la constituye el destino, que lo concibe como aquel espacio concreto conformado por operadores turísticos que interactúan para configurar productivamente el producto turístico existente en el territorio. En cuanto a los elementos de contenido de las relaciones la investigación presta atención a las características reticulares, analizando en este caso la conectividad y el grado de agrupación entre los actores. Respecto a las dimensiones de análisis el trabajo se concentra en los vínculos productivos en términos de proceso productivo turístico -los vínculos los conceptualiza como la conectividad existente entre los sitios web de los operadores turísticos, sustentados en el principio de que la conectividad entre las webs es un fiel reflejo de los vínculos reales que existen entre los operadores (Baggio, 2006; Baggio, Scott, y Wang, 2007; Scott, Baggio y Cooper, 2008b)-. En cuanto al alcance del trabajo se trata de un estudio de caso; yen referencia al objetivo del análisis se concreta en la puesta en evidencia de las relaciones entre los actores turísticos, y no tanto en la vinculación de estas en términos de resultados. Respecto a las técnicas el trabajo utiliza el software de análisis matemático «Pajek» y usa los indicadores de densidad de las relaciones de la red para medir la conectividad y agrupación de los actores y el coeficiente de assortativity. 
En el marco de esta línea de trabajo que antes hemos mencionado encontramos esta vez el trabajo de los tres autores anteriormente nombrados que realizaron en el año 2008 y en el tomando el mismo concepto de destino como compuesto de actores-operadores turísticos y sus relaciones comparan cuatro destinos turísticos de Australia (Scott, Cooper y Baggio, 2008a). Comparte con los otros trabajos de la línea de investigación de estos autores el hecho de que esta investigación utiliza como unidad de análisis el destino concebido este como el conjunto de actores que operan en la realidad turística del territorio, sus elementos de contenido son también las características reticulares de las redes de actores (para este caso la cohesión entre los actores turísticos, las dimensiones de análisis son las vinculaciones que se producen entre los actores en términos de proceso productivo turístico -en este caso conceptualiza los vínculos como los intercambios de información entre los actores turísticos-. El verdadero avance científico de este trabajo está precisamente en el alcance del mismo, ya que utiliza varios casos de estudio para mostrar que las características estructurales de las redes son diferentes en distintos destinos y que el QSNA es muy útil para mostrar estas diferencias estructurales. En cuanto a la metodología y técnicas de investigación que se utilizan en esta investigación consisten en el desarrollo de los indicadores de cohesión estructural que posibilita el análisis matemático de las interacciones, en este caso concreto analiza la densidad relacional, la centralidad de las redes y la clusterización de las mismas.

También en 2008 aparece otro trabajo de los tres autores mencionados en el que se produce una combinación de los principales avances analíticos de los dos trabajos anteriores: por un lado aplican la metodología de estudio de los vínculos de las webs de los operadores turísticos de Elba para analizar otro destino: las islas Fiji; y por otro lado, realizan una comparación de las redes de destinos turísticos para mostrar como los destinos turísticos tienen una configuración de estructuras reticulares distintas y claramente diferenciadas (Scott, Baggio y Cooper, 2008c).

Rodolfo Baggio en colaboración con Luciano da Fontoura Costa realizan otra interesante aportación en el marco de la aplicación del QSNA al estudio del fenómeno turístico. Se trata en esta ocasión de realizar nuevos tipos de análisis utilizando novedosos indicadores propios del análisis reticular y los aplican al caso ya descrito de la isla de Elba. Es decir, se trata de ver diferentes y nuevas propiedades reticulares de un destino turístico aplicando nuevas técnicas de análisis -superedges approach- y mostrando las posibilidades de caracterización turística que las mismas presentan (da Fontoura y Baggio, 2009). Con una misma lógica, es decir, aplicar nuevos instrumentos, técnicas e indicadores del QSNA al turismo se desarrolla en otro trabajo en 2010 en el que sobre el mismo caso de la isla de Elba se aplican técnicas como el Dynamic Processes, Modularity Analysis (Baggio, Scott y Cooper, 2010). Y en la misma línea encontramos también otro trabajo de 2010, en el que sobre el caso de la isla de Elba se aplica la técnica de la Epidemic Difusión Models y cómo a partir de la modelización se pueden proponer procesos de mejora de las interacciones entre los actores turísticos de una red de cara a profundizar en la mejora de los procesos de innovación turística (Baggio y Cooper, 2010).

Suhma S. Bhat y Simon Milne realizan otra significativa aportación a la utilización del QSNA para el estudio del fenómeno turístico a través de un trabajo de investigación que realizan en Nueva Zelanda, al realizar un trabajo de investigación sobre la rede de actores turísticos y sus relaciones para el impulso de acciones de promoción turística del 
destino (Bhat y Milne, 2008). Estos autores estudian las características de la interacción de los diferentes actores turísticos y operadores implicados en el destino de Nueva Zelanda para el impulso de actuaciones de promoción turística de la isla. Desde esta perspectiva ponen de relieve que la centralidad de la red de actores turísticos es un componente básico que influye de manera decisiva en el éxito y la consecución de actuaciones en materia de promoción del destino; de esta manera, en las promociones clásicas que los autores denominan genéricas del destino que son impulsadas por los poderes públicos una excesiva centralidad de estos actores era un elemento que facilitaba el éxito de las acciones de promoción; sin embargo, en el nuevo contexto caracterizado por nuevos factores este tipo de acciones de promoción ya no son efectivas y se hace necesaria una mayor implicación de otros actores del destino, de manera que es más efectiva una red con un mayor número de actores que ocupen posiciones centrales, y por la tanto con una mayor densidad de las relaciones. En este trabajo la unidad de análisis es el destino configurado como los operadores turísticos de un determinado territorio; los elementos de contenido de las relaciones son sus características reticulares; las dimensiones del análisis las vinculaciones en términos del proceso productivo, en este caso se concentra en el ámbito productivo de la promoción turística; en cuanto al alcance utiliza el caso de estudio; y la verdadera novedad que aporta este trabajo es que tiene por objetivo claramente establecido analizar como las características de la red tienen un efecto directo sobre la realidad turística, la centralidad y la densidad influyen de manera decisiva en la efectividad de la puesta en marcha y realización de acciones de promoción turística en el destino; y en cuanto a la metodología y las técnicas utiliza los indicadores de centralidad, densidad y la estructura gráfica de la red para describir las características reticulares de la red de actores turísticos.

Patricia Romero y Carlos Costa aportan otro interesante trabajo en 2010 de aplicación del QSNA al estudio del turismo. En su investigación realizan un análisis de la rede de actores turísticos que existe en el Valle del Jerte (España) y cómo esta red influye en la innovación que en términos turísticos se produce en dicho territorio (Romero y Costa, 2009). La unidad de análisis en este trabajo está constituida por el destino turístico configurado como los actores que intervienen en este sector en un determinado territorio; los elementos de contenido son las características reticulares de la rede de actores turísticos; las dimensiones de análisis están configuradas por las vinculaciones que se producen entre los actores en términos productivos; el alcance del trabajo es el de la exposición de un único caso de estudio; en lo referido al objetivo del análisis se puede poner de manifiesto que se trata de un trabajo que pretende comprobar el efecto que la red tiene sobre la realidad turística (en este caso sobre la innovación); y en lo referente a las técnicas utilizadas aparece el análisis de la centralidad de los actores y la representación gráfica de la red.

En 2010 aparece el trabajo de Michelle Th. McLeod, David R. Vaughan y Jonathan Edwards en el que estudian las redes de transferencia de conocimiento en un destino turístico de Inglaterra. La gran aportación que realizan estos autores tiene que ver con el enfoque del trabajo de investigación ya que analizan las diferencias que se producen entre las redes formales e informales entre actores turísticos para transferir conocimiento en el destino, poniendo de manifiesto que la red formal está caracterizada por una mayor participación de actores, pero que la red informal es más densa y estructurada que la red formal, haciéndose necesario atender al análisis combinado de ambos tipos de redes para comprender realmente 
como se producen las interacciones en términos de conocimiento en un destino turístico (McLeod, Vaughan y Edwards, 2010). En este trabajo la unidad de análisis la constituye claramente el destino turístico como el conjunto de actores turísticos del mismo; los elementos de contenido del trabajo están configurados por las características reticulares de la red de actores turísticos; en cuanto a las dimensiones del análisis podemos decir que están constituidas por las vinculaciones del proceso productivo, concretamente por el conocimiento turístico existente en el destino y cómo se transfiere el mismo; en cuanto al alcance del trabajo de investigación está configurado por el caso de estudio; en cuanto al objetivo del análisis consiste fundamentalmente en poner de manifiesto la influencia que la estructura de la rede de actores turísticos tiene sobre los procesos de transferencia de conocimiento del destino turístico; en lo referido al uso de técnicas de investigación en el trabajo se usan indicadores estructurales como el de equivalencia estructural, el análisis de componentes principales; la densidad de la red y la medida de restricción.

También en 2010 podemos encontrar el trabajo de José M. Brás, Carlos Costa y Dimitrios Buhalis sobre la aplicación del QSNA para el impulso de una ruta del vino en Bairrada (Portugal). En este trabajo de investigación se analiza las interacciones que se producen entre los productores de vino y los operadores turísticos con incidencia en el territorio estudiado con el objetivo de poder proponer un programa de desarrollo turístico que utilice el vino como recurso turístico. En este trabajo se pone de manifiesto que existe una diferencia importante entre las relaciones que realmente se producen entre los actores estudiados en distintos ámbitos socioeconómicos del territorio (medidas por el Índice de Conectividad) y las relaciones que se producen en el marco de la actividad turística entre dichos actores, poniéndose de manifiesto que estas relaciones productivas en el marco de la actividad turística son menos frecuentes y por lo tanto plasman una red con una menor conectividad e intensidad relacional (Brás, Costa y Buhalis, 2010). La unidad de análisis de este trabajo es claramente un proyecto turístico del territorio que conforma el espacio estudiado en el que se pretende impulsar un proyecto turístico en torno a una ruta del vino; los elementos de contenido del estudio lo conforman las características reticulares de la rede de actores analizados; en cuanto a las dimensiones analíticas empleadas están constituidas por los vínculos en términos de proceso productivo (acuerdos comerciales y acciones promocionales) entre los actores implicados en el proyecto turístico, en el que se pone de manifiesto la diferente estructura reticular y el distinto índice de conectividad que presenta la red de actores turísticos de forma comparada entre las relaciones existentes en diferentes ámbitos de la realidad del territorio y la conectividad de las relaciones en materia de acuerdos comerciales turísticos y para el desarrollo de acciones de promoción turística entre los actores analizados; en lo referente al alcance del trabajo se sitúa claramente en el estudio de caso; en cuanto al objetivo del análisis el trabajo de investigación se centra en poner de manifiesto las características de las interrelaciones entre los actores; y en lo referente a los métodos y técnicas empleados en la investigación se utilizan las representaciones gráficas de la estructura reticular a través de sociogramas y el Índice de Conectividad de los actores de la red.

Hilal Erkus-Öztürk y Ayda Eraydin realizan otra interesante aportación a la literatura científica sobre la utilización del QSNA para el estudio del fenómeno turístico. Su trabajo se centra en describir las características diferenciales entre las redes de actores turísticos de la región de Antalya en Turquía en función de si la red es de asuntos económicos o bien de 
asuntos medioambientales, y lo que ponen de manifiesto es que en función del asunto las características reticulares son diferentes tanto en su intensidad, como en su estructura y en las posiciones de centralidad que adquieren diferentes tipos de actores turísticos; de manera que el asunto -economía o medio ambiente- condiciona las características reticulares de las relaciones de colaboración denominadas de gobernanza en el trabajo (Erkus-Öztürk y Eraydin, 2010). La unidad de análisis del trabajo es el destino, estudia como se caracterizan las relaciones entre los operadores turísticos del territorio para un conjunto amplio de actividades susceptibles de ser realizadas colaborativamente que tienen que ver con acciones que son propias de incidir en el destino; en lo que refiere a los elementos de contenido de las relaciones hay que decir que los aspectos estudiados son las características reticulares de las redes de actores (densidad de las relaciones, estructura de posiciones de los actores, vínculos, y centralidad); en lo referido a las dimensiones podemos destacar que estudian los vínculos en términos de producción turística, bien sea en lo referente a acuerdos comerciales o bien para impulsar acciones de mejora medioambiental del destino que acaba afectando a la conformación del producto turístico del territorio; el alcance del trabajo lo constituye el caso de estudio; los objetivos perseguidos tienen que ver más con un perfil descriptivo de la investigación ya que lo que se realiza en el estudio es poner de manifiesto que las redes de gobernanza económica son más densas, presentan un mayor número de actores centrales y la centralidad de las mismas está ocupada por grandes empresas; mientras que las redes de gobernanza medioambiental son menos densas, más centralizadas y lideradas por administraciones públicas y entidades no gubernamentales, por tanto, podemos decir que el estudio no concluye en el efecto que las características de las redes tienen sobre los resultados del turismo de la región estudiada; y en lo que respecta a los métodos y técnicas utilizados el trabajo destaca por analizar la centralidad de los actores, la densidad de las redes y la estructura gráfica de las posiciones de los actores turísticos en la red.

Otro trabajo de aplicación del QSNA al estudio del fenómeno turístico es el realizado por Rafael Merinero en 2011 en el que analiza las características de las redes de los actores turísticos en tres municipios rurales del centro de Portugal (Evoramonte, Mértola y Monsaraz). El principal objetivo analítico de este trabajo es analizar la relación entre las características reticulares de las redes de actores turísticos de las localidades analizadas a través de la densidad, centralidad y la estructura gráfica de las redes y el nivel de desarrollo turístico de estas localidades medido a través del número de visitantes y número de empresas turísticas (Merinero, 2011). La unidad de análisis de este trabajo está conformada por el destino, entendido este como el conjunto de actores turísticos que operan en la actividad turística del territorio; respecto a los elementos de contenido de las relaciones se estudian las características reticulares de las redes de actores; en cuanto a las dimensiones de análisis del estudio están conformadas por los vínculos entre los actores en términos del proceso productivo turístico del destino; en referencia al alcance el trabajo de investigación se centra en el estudio de tres casos los cuales compara en cuanto a sus diferencias reticulares; el objetivo del análisis no es descriptivo, sino que el trabajo pretende aportar información sobre la interrelación que existe entre las características de las redes y el resultado turístico del territorio, es decir, su nivel de desarrollo turístico; respecto a los métodos y técnicas el trabajo de investigación utiliza la centralidad de los actores, la densidad y la estructura de la red expresada a través de su representación gráfica. 
También en 2011 aparece el trabajo realizado por Rodolfo Baggio en el que trata de ver la influencia que tiene en las características de la red turística de un determinado destino la configuración no homogénea de tipos de actores, poniendo de manifiesto que la ubicación geográfica de los actores, el tipo de empresa y el tamaño de la misma condicionan la estructura de la red turística (Baggio, 2011). La unidad de análisis de este trabajo es el destino, concretamente la isla de Elba en Italia; los elementos de contenido de las relaciones son las propiedades reticulares de la red; las dimensiones de análisis son las vinculaciones en términos de actividad productiva entre los actores turísticos; el alcance del trabajo es el estudio de caso; el objetivo del análisis es la descripción de las características reticulares de la red pero no su incidencia en los resultados turísticos del territorio analizado; y en cuanto a la metodología empleada aplica los métodos de análisis de modularidad.

En 2012 podemos encontrar otro interesante trabajo que utiliza el QSNA para caracterizar el fenómeno turístico, concretamente se trata del trabajo realizado por Seldjan Timur sobre las redes de colaboración de actores en tres destinos turísticos urbanos (Calgary, Victoria y San Francisco) con el objetivo de poder comprobar las posiciones de centralidad de los actores turísticos en dichas redes (Timur, 2012). En este trabajo de investigación la unidad de análisis está conformada de una manera clara por el destino, conformado por un conjunto de actores que tienen relaciones de diverso tipo entre ellos; los elementos de contenido del trabajo de investigación lo constituyen las características reticulares de las redes de actores turísticos de las ciudades, en este caso el trabajo pone de manifiesto cuales son los actores que ocupan posiciones de centralidad en las redes turísticas, siendo por tanto actores importantes en la configuración de las acciones conjuntas que se ponen en marcha en cada uno de los destinos urbanos analizados; las dimensiones de análisis están formadas por las interacciones entre los actores turísticos en términos productivos que tienen lugar en el destino urbano; el alcance del trabajo de investigación lo configura el estudio de casos, concretamente se analizan las redes de actores de tres ciudades; en lo que se refiere al objetivo del análisis podemos decir que es fundamentalmente descriptivo, la comparación de los casos y su exposición tiene por objetivo fundamental poner de manifiesto cuales son los actores turísticos más centrales, es decir que ocupan posiciones en la red turística de mayor importancia pudiéndose comprobar que para los tres casos analizados son los organizaciones que actúan de Destination Management Organization (DMO) las que ocupan las posiciones más centrales de las redes seguidas de los hoteles y las administraciones públicas locales, el trabajo por tanto no pretende poner de manifiesto como las características reticulares tienen una incidencia en la actividad turística en términos de resultados para el destino o el tipo de impacto que tienen sobre el mismo; en cuanto a los métodos y técnicas utilizadas en el trabajo encontramos la representación gráfica de la estructura de la red y el análisis del grado de centralidad de los actores turísticos.

Del año 2012 es el trabajo realizado por Gonzalo Matías y Juan Ignacio Pulido en el que analizan la dinámica relacional entre las organizaciones que participan en la actividad turística de los municipios de Villa Gesell y Pinamar en Argentina y su nivel de desarrollo turístico (Matías y Pulido, 2012); este trabajo sigue la línea de investigación propuesta por el trabajo anteriormente expuesto de Rafael Merinero (Merinero, 2011). La unidad de análisis del trabajo está conformada por el destino turístico definido como los actores turísticos y sus vínculos; los elementos de contenido de las relaciones hacen referencia 
a las características reticulares de las mismas analizadas a través de la estructura gráfica de las redes en términos de representación gráfica y de la densidad de las relaciones; las dimensiones de análisis son las vinculaciones que existen entre los actores en términos de proceso productivo turístico; el alcance del trabajo está conformado por dos estudios de caso; en cuanto a al objetivo del análisis se pretende comprobar la interrelación que existe entre el nivel de desarrollo turístico y las características de las redes de actores; y en relación a la metodología y las técnicas en el trabajo s emplean la densidad de las relaciones y la representación gráfica de las relaciones donde se pueden comprobar las posiciones que ocupan los actores en la red del destino.

Recientemente, en el año 2013 encontramos otro trabajo que aplica el QSNA al estudio del fenómeno turístico, se trata de los autores Albert N. Kimbu y Michael Z. Ngoasong que analizan la participación de los diferentes actores turísticos en la formulación de la política turística de Camerún, a través de la presentación de un mapa de los principales operadores turísticos y los vínculos que se establecen entre ellos (Kimbu y Ngoasong, 2013). La unidad de análisis de este trabajo es la política turística; los elementos de contenido de las relaciones están claramente conformados por las características reticulares, en este caso por las posiciones de centralidad en la estructura de la rede de actores turísticos que intervienen en la política turística del país; las dimensiones del análisis están configuradas por los vínculos que se producen entre los operadores turísticos analizados; el alcance del trabajo es el estudio de caso; el objetivo del análisis está en describir la red de relaciones de los actores turísticos que participan en la formulación de la política turística de Camerún con la finalidad principal de destacar cuales son los actores que ocupan posiciones de centralidad en dicha red de política turística y cómo son los vínculos que se producen entre estos actores y el resto; en cuanto a la metodología empleada se trata de la representación gráfica de la red a través de un sociograma y de la descripción de la centralidad de los diferentes actores en la estructura de la red.

Entre los años 2012 y 2013 encontramos otro trabajo que aplica el QSNA para estudiar el turismo, se trata del estudio llevado a cabo por José María Prat Forga y Gemma Cànoves Valiente para describir las características de las redes de los actores turísticos en el desarrollo del turismo industrial en Cataluña. En el trabajo de 2012 analizan la red Xatic impulsada por el gobierno de la Generalitat de Catalunya para impulsar el desarrollo turístico en torno al patrimonio industrial en la región, concretamente el análisis pretende poner de manifiesto la estructura de la red y cuales son los actores turísticos que ocupan las posiciones centrales en las relaciones. En cuanto al trabajo de 2013 el objetivo del trabajo consiste en analizar las redes de actores en turismo industrial en dos comarcas de la región de Cataluña con el claro objetivo de poner de manifiesto que actores ocupan el papel central en dichas redes que pretenden impulsar desarrollo turístico utilizando patrimonio industrial (Cànoves y Prat, 2012; Prat y Cànoves, 2013). La investigación tienen como unidad de análisis el destino, es decir, el conjunto de actores turísticos que trabajen en el impulso del desarrollo industrial en los ámbitos territoriales analizados; los elementos de contenido de las relaciones son claramente sus características reticulares, centrándose en la exposición del gráfico de las relaciones y la descripción del grado de centralidad y de intermediación de los actores; las dimensiones del análisis las constituyen los vínculos productivos entre los actores turísticos; el alcance del análisis es el estudio de caso, un solo caso para el primer trabajo y dos casos 
para el segundo trabajo; el objetivo del análisis hemos encontrado que es claramente descriptivo, se trata de poner de manifiesto la estructura reticular de la rede de actores y cuales de dichos actores ocupan una posición central en la misma jugando un papel claro de liderazgo en el desarrollo del turismo industrial, de manera que para el primer estudio la posición central la ocupa la Generalitat y en el segundo de los trabajos ponen de manifiesto el papel central que tienen las administraciones públicas en el impulso de proyecto de desarrollo turístico industrial. En ningún momento del trabajo se pretende evidenciar el impacto que las características de las redes tienen sobre la actividad turística de los destinos analizados; en lo referente a la metodología empleada utilizan la representación gráfica de la red a través de sociogramas, el grado de centralidad, la densidad de la red y el grado de intermediación.

VikkiSchaffer y Merediith Lawley aportan otro interesante trabajo en 2012 en el que analizan las características de una red de actores con el objetivo de comprobar como se producen los flujos de información en relación a la necesidad protección de un arrecife artificial de una isla que constituye un recurso de gran importancia como atractivo turístico (Schaffer y Lawley, 2012). La unidad de análisis está constituida por un proyecto turístico en torno a la protección de un espacio natural; los elementos de contenido son las características reticulares de la red; las dimensiones del análisis están vinculadas a la importancia de transferir información tendente a la protección del recurso natural, por tanto en la necesaria toma de conciencia en lo referente a la creación y gestión de un elemento productivo del destino turístico como es un recurso natural del mismo; el alcance está configurado por el caso de estudio; y el objetivo del análisis tiene un objetivo explicativo ya que pretende ver como la red influye en el resultado, en este caso sobre la información necesaria para que no decaiga el interés en la protección del recurso natural clave del destino turístico; y en lo referente a la metodología utiliza la representación gráfica de la red, la densidad, la cohesión y la distancia entre los nodos.

Otro trabajo de aplicación del QSNA al estudio del turismo es el realizado por Ana Muñoz y Laura Fuentes en el que estudian las características de las redes de actores del destino turístico en el ámbito productivo de la promoción turística (Muñoz y Fuentes, 2013). La unidad de análisis está constituida por el destino turístico como el conjunto de actores que operan en esta actividad en un determinado territorio; los elementos de contenido de las relaciones son las características reticulares de las redes de relación; las dimensiones de análisis son los vínculos en términos de proceso productivo turístico del destino, en este caso concreto las relaciones que se establecen para promocionar un destino; el alcance del trabajo es el estudio de un caso; el objetivo del análisis es puramente descriptivo intentando poner de relieve las características de las redes de los actores públicos y privados que intervienen en las acciones de promoción del destino turístico analizado; en cuanto a los métodos y las técnicas empleados utilizan la representación gráfica, el grado de centralidad de los actores, el índice relativo de centralidad, el grado de intermediación, la densidad, la integración y la centralización de la red.

También de reciente aparición es el trabajo de José María Prat que en 2013 realiza un trabajo de investigación en el que compara las redes de actores turísticos de tres destinos de turismo industrial (Berguedà en Cataluña, Haut Rhin en Alemania y South Lanarkshire en Escocia) y su nivel de desarrollo turístico (Prat, 2013). La unidad de análisis de este 
trabajo de investigación es el destino turístico conformado por el conjunto de actores y sus vínculos; los elementos de contenido de las relaciones están configurados por las características reticulares de las redes de actores; las dimensiones del análisis son las vinculaciones entre los actores en términos de proceso productivo; el alcance del trabajo de investigación son dos estudios de caso; el objetivo del análisis consiste en establecer la relación entre las características de las redes de actores turísticos y el nivel de desarrollo del destino medido en términos del número de visitantes que recibe el destino; en cuanto a los métodos y técnicas empleados en el análisis hay que decir que utilizan la densidad de las relaciones y la distancia media. Este trabajo al igual que el de Matías y Pulido (2012) va en la misma línea de investigación planteada por Merinero (2011).

En el escenario reciente de la aplicación del QSNA al estudio del turismo aparece en 2013 un trabajo que no aplica la metodología al análisis del fenómeno turístico sino a la estructura de producción científica del análisis turístico a través de los procesos de cocitación entre los más importantes autores e investigadores, poniendo de relieve como se configura una red de científicos y de investigaciones a través de las citas que aparecen en dichos trabajos. Se trata de identificar en esa red de citas cuales son los actores más centrales y por lo tanto más influyentes en la producción de conocimiento sobre el turismo (Benckendorff y Zehrer, 2013).

Recientemente ha aparecido el trabajo realizado por Rodolfo Baggio en el que desarrolla una innovadora propuesta basada en la traducción de series temporales de visitantes de un determinado destino en datos de redes para analizar su conformación reticular (Baggio, 2013). Lo que este trabajo tiene realmente de novedoso es la obtención de los datos reticulares que son el resultado de la aplicación de un algoritmo que traduce el dato de visitantes de un determinado destino a un dato relacional y así obtiene una matriz de adyacencia a la que puede aplicarle análisis cuantitativos. La unidad de análisis del trabajo de investigación es el destino turístico (Italia y la isla de Elba); los elementos de contenido lo conforman las propiedades reticulares de la red obtenida; las dimensiones utilizadas están compuestas por los vínculos en términos productivos, ya que la red aporta información de los resultados turísticos de un determinado territorio en términos de visitantes del mismo; el alcance del trabajo de investigación es de dos casos de estudio; en cuanto al objetivo del análisis consiste en la simple exposición de las características de las redes sin exponer ningún tipo de impacto en términos de resultado sobre la actividad turística de los casos de estudio; y en cuanto a los métodos y técnicas utilizados el trabajo emplea el densidad de grado de las redes y el coeficiente de clusterización de las mismas.

\section{LA AGENDA DE INVESTIGACIÓN DEL QSNA APLICADA AL TURISMO: PRESENTE Y FUTURO}

En la siguiente tabla realizamos una exposición de las principales características metodológicas de los trabajos encontrados en al literatura científica sobre QSNA y turismo que han sido presentados anteriormente. Y aportamos una representación gráfica de dicha literatura en función de cada una de las cuatro dimensiones utilizadas para clasificar dicha literatura científica (unidad de análisis, objetivo del análisis; alcance del estudio, métodos y técnicas utilizados) 


\section{Cuadro 2}

\section{CARACTERÍSTICAS METODOLÓGICAS DE LOS TRABAJOS SOBRE QSNA Y TURISMO}

\begin{tabular}{|c|c|c|c|c|}
\hline Autor & Unidad de análisis & Objetivo del análisis & Alcance del estudio & Métodos y técnicas \\
\hline Cobb, 1990 & Análisis de un plan turístico & Incidencia de la red en la actividad turística & Estudio de un caso & Centralidad de los actores de la red \\
\hline Stokowski, 1990 & Personas consumidoras & Incidencia de la red en la actividad turística & Estudio de un caso & Centralidad de los actores de la red \\
\hline Stokowski y Lee, 1991 & Personas consumidoras & Incidencia de la red en la actividad turística & Estudio de un caso & Centralidad de los actores de la red \\
\hline Urry, 2003 & Personas consumidoras & Incidencia de la red en la actividad turística & Estudio de un caso & Centralidad de los actores de la red \\
\hline Pavlovich, 2003 & Análisis destino turístico & Incidencia de la red en la actividad turística & Estudio de un caso & Densidad y centralización de la red \\
\hline Jones, 2005 & Análisis proyecto turístico & Descripción de las relaciones & Estudio de un caso & Gráfico de la red \\
\hline Pforr, 2006 & Análisis política turística & Descripción de las relaciones & Estudio de un caso & Centralidad de los actores de la red \\
\hline Shih, 2006 & Análisis del destino & Incidencia de la red en la actividad turística & Estudio de un caso & Centralidad de los nodos de la red \\
\hline Scott, Cooper,y Baggio, 2007 & Análisis del destino & Incidencia de la red en la actividad turística & Estudio de un caso & Exposición de métodos y técnicas \\
\hline Baggio, 2007 & Análisis del destino & Descripción de las relaciones & Estudio de un caso & Densidad de la red y coeficiente de asociatividad \\
\hline Baggio, 2006 & Análisis del destino & Descripción de las relaciones & Estudio de un caso & Densidad de la red y centralidad de los actores \\
\hline Baggio, Scott, y Wang, 2007 & Análisis del destino & Descripción de las relaciones & Estudio de un caso & Densidad y representación gráfica \\
\hline Scott, Baggio y Cooper, 2008b & Análisis del destino & Descripción de las relaciones & Estudio de un caso & $\begin{array}{l}\text { Grado, densidad, centralidad de salida y entrada y } \\
\text { representación gráica }\end{array}$ \\
\hline Scott,Cooper y Baggio, 2008a & Análisis del destino & Descripción de las relaciones & Estudio de cuatro casos & Densidad, centralización y clusterización de las redes \\
\hline Scott, Baggio y Cooper, 2008c & Análisis del destino & Descripción de las relaciones & Estudio de dos casos & Densidad, centralización y clusterización de las redes \\
\hline da Fontoura y Boggio, 2009 & Análisis del destino & Descripción de las relaciones & Estudio de un caso & Superedgesapproach \\
\hline Baggio, Scott y Cooper, 2010 & Análisis del destino & Descripción de las relaciones & Estudio de un caso & \begin{tabular}{|l|} 
DynamicProcesses, \\
ModularityAnalysis \\
\end{tabular} \\
\hline Baggio y Cooper, 2010 & Análisis del destino & Descripciónn de las relaciones & Estudio de un caso & Epidemic Difusión Models \\
\hline Bhat y Milne, 2008 & Análisis del destino & Incidencia de la red en la actividad turística & Estudio de un caso & Centralidad de los actores \\
\hline Romero y Costa, 2009 & Análisis del destino & Incidencia de la red en la actividad turística & Estudio de un caso & Centralidad de los actores y representación gráfica \\
\hline McLeod, Vaughan y Edwards, 2010 & Análisis del destino & Incidencia de la red en la actividad turística & Estudio de un caso & $\begin{array}{l}\text { Equivalencia estructural, análisis de componentes principales } \\
\text { y medida de restricción }\end{array}$ \\
\hline Brás, Costa y Buhalis, 2010 & Proyecto turístico & Descripción de las relaciones & Estudio de un caso & Representación gráfica e índice de conectividad \\
\hline Erkus-Öztuirk y Eraydin, 2010 & Análisis del destino & Descripción de las relaciones & Estudio de un caso & Densidad, centralidad de los actores y representación gráica \\
\hline Merinero, 2011 & Análisis del destino & Incidencia de la red en la actividad turística & Estudio de tres casos & $\begin{array}{l}\text { Densidad, centralidad de los actores, grado de intermediación } \\
\text { y representación gráica }\end{array}$ \\
\hline Baggio, 2011 & Análisis del destino & Descripción de las relaciones & Estudio de un caso & Análisis de modularidad \\
\hline Timur, 2012 & Análisis del destino & Descripción de las relaciones & Estudio de dos casos & Representación gráfica y centralidad de los actores \\
\hline Matías y Pulido, 2012 & Análisis del destino & Incidencia de la red en la actividad turística & Estudio de dos casos & Representación gráfica y centralidad de los actores \\
\hline Kimbu y Ngoasong, 2013 & Política turística & Descripción de las relaciones & Estudio de un caso & Representación gráica y centralidad de los actores \\
\hline Cànoves y Prat, 2012 & Análisis del destino & Descripción de las relaciones & Estudio de un caso & $\begin{array}{l}\text { Representación gráfica, grado de centralidad de los actores, } \\
\text { densidad de la red y grado de intermediación }\end{array}$ \\
\hline Prat y Cànoves, 2013 & Análisis del destino & Descripción de las relaciones & Estudio de dos casos & $\begin{array}{l}\text { Representación gráfica, grado de centralidad de los actores, } \\
\text { densidad de la red y grado de intermediación }\end{array}$ \\
\hline Schaffer y Lawley, 2012 & Proyecto turístico & Incidencia de la red en la actividad turística & Estudio de un caso & Representación gráfica, densidad, cohesión y distancia geodésica \\
\hline Muñoz y Fuentes, 2013 & Destino turístico & Descripción de las relaciones & Estudio de un caso & $\begin{array}{l}\text { Representación gráíca, el grado de centralidad de los actores, } \\
\text { el índice relativo de centralidad, el grado de intermediación, la } \\
\text { densidad, la integración y la centralización de la red. }\end{array}$ \\
\hline Prat, 2013 & Análisis del destino & Incidencia de la red en la actividad turística & Estudio de tres casos & Densidad de la red \\
\hline Baggio, 2013 & Análisis del destino & Descripción de las relaciones & Estudio de dos casos & $\begin{array}{l}\text { Aplicación de algoritmos a número de visitantes, densidad de la } \\
\text { red y coeficiente de clusterización }\end{array}$ \\
\hline Benckendorff y Zehrer, 2013 & $\begin{array}{l}\text { Análisis producción } \\
\text { científica turismo }\end{array}$ & Descripción de las relaciones & Estudio de dos casos & Centralidad de los actores \\
\hline
\end{tabular}

Fuente: Elaboración propia. 


\section{Figura 1 \\ LITERATURA CIENTÍFICA SEGÚN UNIDAD Y OBJETIVO DE ANÁLISIS ( $\mathrm{n}^{0}$ de obras científicas: 35 )}

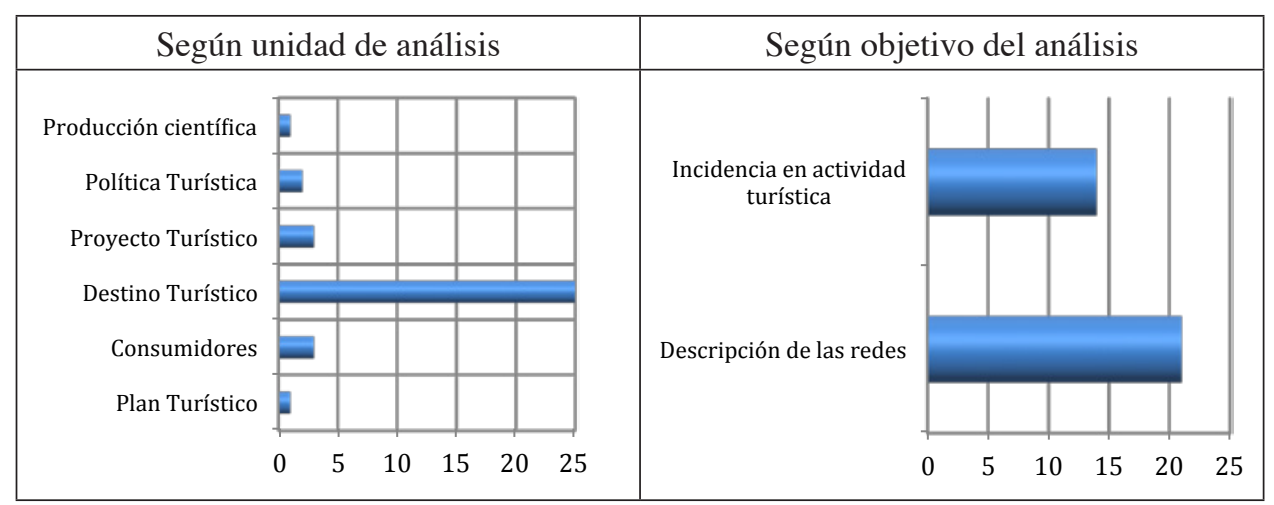

Fuente: Elaboración propia.

Figura 2

\section{LITERATURA CIENTÍFICA SEGÚN ALCANCE DEL ESTUDIO Y MÉTODOS Y TÉCNICAS USADOS ( $n^{\circ}$ de obras científicas: 35 )}

\begin{tabular}{|c|c|c|c|c|}
\hline Según el alcance del estudio & Según métodos y técnicas usados \\
\hline Cuatro casos de estudio & $\begin{array}{c}\text { Equivalencia } \\
\text { estructural } \\
\text { Tres casos de estudio }\end{array}$ Análisis modular \\
Dos casos de estudio & $\begin{array}{c}\text { Medidas cohesión } \\
\text { (agrupación) } \\
\text { Medidas cohesión } \\
\text { (centralidad) } \\
\text { Representación } \\
\text { gráfica }\end{array}$ & \\
\hline
\end{tabular}

Fuente: Elaboración propia.

Como se puede desprender de un análisis de la información expuesta en la tabla anterior, podemos mantener que la aplicación del QSNA para el estudio del turismo ha presentado una clara línea de trabajo caracterizada por el predominio de trabajos de investigación que tienen como unidad de análisis el destino, el alcance de dichos trabajos se caracteriza por presentar una descripción de las relaciones, centradas en la exposición de un solo caso de estudio y la utilización de los indicadores de densidad de las redes y la centralidad de los actores.

Por tanto, podemos mantener que existen muy pocos trabajos de investigación hasta la actualidad que utilicen el QSNA para analizar la incidencia que las relaciones entre los actores tienen sobre el turismo, es decir, el efecto que las redes tienen sobre los resultados 
de la realidad turística que se trata de analizar. Y en los pocos trabajos que hemos encontrado en la literatura científica centrados en la incidencia de las redes se aplican a un solo caso de estudio y utiliza los indicadores de centralidad de actores y la densidad relacional.

Si ponemos la atención sobre las técnicas utilizadas podemos comprobar que predomina el uso de los indicadores de cohesión de las redes (centralidad de los actores, densidad de la red, representación gráfica de la red, grado de intermediación e índice de clusterización), y no existe ningún trabajo que estudio los indicadores de agrupamiento de las redes. Podemos encontrar también algunos trabajos de investigación que aplican técnicas e indicadores más avanzados como por ejemplo los análisis dinámicos, los análisis modulares, el desarrollo de algoritmos y equivalencia estructural; pero todos estos trabajos están centrados en un enfoque descriptivo y se aplica a un solo caso de estudio.

Podemos mantener que la aplicación del QSNA al estudio del turismo aparecida en la literatura científica ha presentado en estos últimos años elementos suficientemente positivos para poder mejorar el conocimiento del fenómeno turístico desde una perspectiva relacional, al poner de manifiesto que la estructura reticular de las redes que sustentan la actividad turística es un componente fundamental de la misma. Sin embargo, consideramos, como se deriva de la exposición de las características de los trabajos expuesta en el apartado anterior, que es necesario seguir avanzando en la investigación sobre el turismo a partir del QSNA ya que de una manera muy importante predominan los trabajos de investigación de un solo caso y los centrados en la descripción de las características de las redes.

Desde esta perspectiva, pensamos que una de las grandes oportunidades que ofrece el análisis reticular de las redes no se ha aprovechado en toda su extensión: la posibilidad de comprobar el efecto y la incidencia que las redes tienen sobre los resultados y el rendimiento de la actividad turística. Por lo tanto, es necesario que pongamos de manifiesto la necesidad de reclamar trabajos de investigación que contribuyan a establecer de manera clara la interacción que se produce entre las características de las redes de actores que sustentan un determinado destino turístico y el nivel de desarrollo turístico -resultado y rendimiento- en el sentido de la tesis ampliamente mantenida de que a medida que aumenta el nivel de desarrollo turístico de un determinado territorio también lo hacen las redes del mismo en la dirección de una mayor intensidad relacional (Zehrer y Raich, 2010), promoviendo de esta manera la apertura de nuevas perspectivas para aplicar QSNA para mejorar la comprensión del fenómeno del turismo (Baggio, Scott y Cooper, 2010: 819).

A partir de esto, está claro cual debe de ser la primera de las propuestas para avanzar en la futura agenda de investigación del turismo desde el QSNA: el desarrollo de trabajos que incluyan un número amplio de casos, es decir, de redes de destino, para poder avanzar en la presentación de una más clara evidencia de cómo las características de diferentes redes tienen una incidencia en el nivel de desarrollo y de resultado de la actividad turística sobre los territorios. Si disponemos de múltiples casos y nos ayudamos de la aplicación de técnicas estadísticas podremos avanzar en una mayor visibilidad de cómo las diferencias de las redes se (co)relacionan con el nivel de desarrollo y el rendimiento turístico. Para esta primera propuesta de avance en la agenda de investigación se pueden utilizar los indicadores básicos y medidas de cohesión de las redes que durante todos estos años han sido desarrolladas en la literatura científica y que analíticamente han funcionado bien en los estudio de caso realizados hasta ahora. 
Pero, al mismo tiempo que mejoramos con estudios comparados de redes utilizando medidas de cohesión básicas, es necesario proponer otro avance en términos de la utilización de nuevas medidas de redes, especialmente las que utilizan indicadores de agrupación y los análisis de equivalencia estructural (que han sido muy poco utilizados) con la orientación espacial de valorar la incidencia de estos indicadores en los resultados turísticos de dichas redes. Estos trabajos en un futuro inmediato pueden estar dominados por el estudio de caso para mejorar en la pericia analítica de dichos indicadores y su vinculación en términos de rendimiento turístico para el territorio, para que un periodo de tiempo no muy amplio se puedan desarrollar trabajos de investigación amplios en términos del número de casos para poder realizar comprobaciones en términos estadísticos que permitan mejorar la visibilidad analítica de la influencia de estos aspectos estructurales de las redes y el nivel de desarrollo turístico alcanzado en distintos territorios.

\section{CONCLUSIONES}

De todo lo expuesto hasta ahora podemos extraer al menos cinco grandes conclusiones. La primera de ellas es que la literatura científica sobre QSNA aplicada al turismo ha aportado importantes avances analíticos para la comprensión del fenómeno del turismo. En segundo lugar, la mayor parte de los trabajos de investigación han tenido hasta ahora una clara orientación analítica conformada en torno a la utilización de indicadores reticulares básicos de cohesion de las redes (densidad, centralidad, intermediación, y análisis gráficos) aplicadas a uno o muy pocos casos de estudio y con una clara voluntad descriptiva más que explicativa.

Por tanto, a partir de esto, podemos reclamar, como tercera gran conslusión, la propuesta de que el primer avance en la agenda de investigación sobre el QSNA sobre el turismo sea el de impulsar estudios comparados sobre un número importante de casos para que de una forma más consluyente podamos aportar explicaciones de cómo estas propiedades reticulares de cohesion inciden sobre los resultados turísticos de un determinado territorio.

En cuarto lugar, es necesario seguir incrementando los trabajos de investigación de cara a mejorar nuestro conocimiento, especialmente en aquellos aspectos, que sobre la base de las características de los trabajos que han aparecido hasta ahora, no han sido tratados, y que podríamos considerar que son la aplicación de medidas de subgrupos, de equivalencia estructural y de algoritmos. Estos análisis sería interesante desarrollarlos en estudios comparados entre casos para ver como estas características reticulares influyen sobre los resultados turíticos de un determinado territorio.

Y como última gran conclusion creemos también necesario que la agenda de investigación sobre QSNA aplicada al turismo debe de avanzar en su combinación con la aplicación de técnicas cualitativas que nos permitan aportar explicaciones de porqué las propiedades reticulares tienen una determinada incidencia en los resultados de la actividad turística en un determinado territorio.

\section{BIBLIOGRAFÍA}

BAGGIO, R. (2006): «Complex systems, information technologies and tourism: a network point of view». Information Technology and Tourism, 8(1), 15-29. 
BAGGIO, R., SCOTT, N. y WANG, Z. (2007): «What network analysis of the WWW can tell us about the organization of tourism destinations». Proceedings of CAUTHE 2007, Sydney, Australia, 11-14, February.

BAGGIO, R. (2007): «The web graph of a tourism system». Physica A, 379(2), 727-734.

BAGGIO, R., SCOTT, N. y COOPER, CH. (2010): «Network Science: A Review Focused on Tourism». Annals of Tourism Research, vol. 37, No 3, pp. 802-827.

BAGGIO, R., y COOPER, CH. (2010): «Knowledge transfer in a tourism destination: the effect sof a network structure». The Service Industrial Journal, vol. $30 \mathrm{n}^{\circ}$ 10, pp. 1757-1771.

BAGGIO, R. (2011): «Collaboration and cooperation in a tourism destination: a network science approach». Current Issues in Tourism, vol. 14 (2), pp. 183-189.

BAGGIO, R. (2013): «Studying complex tourism Systems: a novel approach based on Networks derived from a time series». XIV April International Academic Conference on Economic and Social development, Moscow, April 2-5.

BENCKENDORFF, P. y ZEHRER, A. (2013): «A network analysis of tourism research». Annals of Tourism Research, vol. 43, pp. 121-149.

BENI, M.C. (1993): «Sistemas de turismo SISTUR. Estudio del turismo frente a la nueva teoría de los sistemas». Estudios y Perspectivas en Turismo, 2(1): 7-26.

BHAT, S.S. y MILNE, S. (2008): «Network effects on cooperation in destination web site development». Tourism Management, vol. 29, pp. 1131-1140.

BRAMWELL, B. y LANE, B. (2000): «Collaboration and paterships in tourism planning», en Bramwell, B. y Lane, B., Tourism Collaboration and partnerships. Politics, practice and sustainability. Channel View Publications. Clevedon.

BRAS, J.M., COSTA, C. y BUHALIS, D. (2010): «Network analysis and wine routes: the case of the Bairrada Wine Route». The Service Industries Journal, vol. 30, $\mathrm{n}^{\circ} 10$, pp. 1621-1641.

CÂNOVES, G., y PRAT, J.M. (2012): «Las asociaciones como eje vertebrador del desarrollo turístico industrial: la red XATIC y el turismo industrial en Cataluña», Revista de Análisis Turístico, $\mathrm{n}^{\circ}$ 13, pp. 49-56

BURT, R.S. y MINOR, M.J. (1983): Aplied Network Analysis. Sage, Beverly Hills.

COBB, M. (1990): Influence and Exchange Networks among tourism oriented Business in four Michigan communities. Michigan State University, East Lasing.

COHEN, E. (1984): «The sociology of tourism: Approaches, issues and findings». Annual Review of Sociology, 10, 373-392.

COHEN, E. y COHEN, S. A. (2012): «Current sociological theories and issues in tourism». Annals of Tourism Research, 39(4), 2177-2202.

DA FONTURA COSTA, L. y BAGGIO, R. (2009): «The web of connections between tourism companies: Structure and dynamics». Physica A, nº 388, pp. 4286-4296.

DE KADT, E. (1979): «Social planning for tourism in the developing countries». Annals of Tourism Research, 6(1), 36-48.

ERKUS-ÖZTÜRK, H. y ERAYDIN, A. (2010): «Enviromental governance for sustainable tourism development: Collaborative Networks and organization building in the Antalya tourism region». Tourism Management, vol. 31, pp. 113-124.

GRACI, S. (2013): «Collaboration and Partnership Development for Sustainable Tourism». Tourism Geographies, 15(1), 25-42. 
GUNN, C. A. (1994): Tourism Planning: Basics, Concepts, Cases. Third Edition. Washington DC: Taylor \& Francis.

HENDEE, J. C. (1975): «Sociology and applied leisure research». Annals of Tourism Research, 2(3), 155-162.

JAFARI, J. (1974): «The components and nature of tourism. The tourism market basket of goods and services». Annals of Tourism Research, 3(1), 73-89.

JONES, S. (2005): «Community-based ecotourism: The significance of social capital». Annals of Tourism Research, 32(2), 303-324.

KEOGH, B. (1990): «Public participation in community tourism planning». Annals of Tourism Research, 17(3), 449-465.

KNOKE, D. y KUKLINSKI (1982): «Network Analysis». Series Quantitative Applications in the Social Science, $\mathrm{n}^{\circ} 28$. Sage, London.

KIMBU, A.N. y NGOASONG, M.Z. (2013): «Centralised decentralization of tourism development: A network perspective». Annals of Tourism Research, vol. 40, pp. 235-259.

MATÍAS, G. y PULIDO, J.I. (2012): «Dinámica relacional interorganizacional para el desarrollo turístico. Los casos de Villa Gesell y Pinamar (Argentina)». Revista de Estudios Regionales, n ${ }^{\circ}$ 94, pp. 167-194.

KRIPPENDORF, J. (1982): «Towards new tourism policies. The importance of environmental and sociocultural factors». Tourism Management, 3(3), 135-148.

LAWS, E., SCOTT, N. y PARFITT, N. (2002): «Synergies in destination image management: a case study and conceptualization». International Journal of Tourism Research, 4(1), 39-55.

LAZZERETTI, L. y PETRILLO, C.S. (2006): Tourism Local Systems and Networking. Elsevier, Amsterdam.

LEIPER, N. (1979): «The framework of tourism: Towards a definition of tourism, tourist, and the tourist industry». Annals of Tourism Research, 6(4), 390-407.

MARSDEN, P.V. y LIN, N. (1982): Social Structure and Network Analysis. Sage, Beverly Hills.

MCLEOD, M., VAUGHAN, T. y EDWARDS, J. (2010): «Knowled Networks in the tourism sector of the Bournemouth, Poole, and Christchurch conurbation: preliminary analysis». The Service Industries Journal, vol. 10, $\mathrm{n}^{\circ}$ 30, pp. 1651-1667.

MERINERO, R. (2011): «Redes de actores y desarrollo turístico: estudio de casos en Portugal». Revista de Análisis Turístico, nº 11, pp. 9-21.

MERINERO, R. (2012): «Las redes de actores en la gestión activa de los destinos turísticos: elaboración de un modelo de análisis». EAE-LAP Lambert Academic Publishing, Berlín.

MICHAEL, E.J. (2007): Micro-clusters and Networks: The Growth of Tourism. Elsevier, Amsterdam.

MOLINA, J.L. (2001): El análisis de redes sociales. Una introducción. Ediciones Bellaterra, Barcelona.

MUÑOZ, A. y FUENTES, L. (2013): «La cooperación publico privada en el ámbito de la promoción de los destinos. El análisis de redes sociales como propuesta metodológica». Cuadernos de Turismo, no 31, pp. 199-223. 
NASH, D. y SMITH, V.L. (1991): «Anthropology and tourism». Annals of Tourism Research, 18(1), 12-25.

NOVELLI, M., SCHMITZ, B., y SPENCER, T. (2006): «Networks, cluster and innovation in tourism: A UK experience». Tourism Management, 27(6), 1141-1152.

PAVLOVICH, K. (2003): «The evolution and transformation of a tourism destination network: The Waitomo Caves, New Zealand». Tourism Management, 24(2), 203-216.

PFORR, C. (2006): «Tourism Policy in the Making: An Australian Network Study». Annals of Tourism Research, 33(1), 87-108.

PRAT, J.M. y CÀNOVES, G. (2013): «La centralidad de las administraciones públicas en las redes sociales del turismo industrial. Una comparación entre Bages- y el HautRhin». Pasos. Revista de Turismo y Patrimonio, vol. 11, n 4, pp. 513-524.

PRAT, J.M. (2013): «La distancia geográfica y social como factores a considerar en el desarrollo del turismo industrial y sus redes sociales». Revista de Análisis Turístico, $\mathrm{n}^{\circ}$ 15 , pp. 49-59.

REQUENA, F. (2003): «Análisis de redes sociales». CIS, Madrid.

RICHTER, L.K. (1983). «Tourism politics and political science: A case of not so benign neglect». Annals of Tourism Research, 10(3), 313-335.

ROMERO, P. y COSTA, C. (2009): «The potencial of Management Networks in the innovation and competitiveness of rural tourism: a case study on the Valle del Jerte (Spain) ». Current Issues in Tourism, vol. 13 (1), pp: 75-91.

SHAFFER, V. y LAWLEY, M. (2012): «An analysis of the Networks evolving from an artificial reef development». Current Issues in Tourism, vol. 15 (5), pp: 497-503.

SCHULTE, S. (2003): Guía conceptual y metodológica para el desarrollo y planificación del sector del turismo. CEPAL. Serie Manuales. Santiago de Chile.

SCOTT, J. (2000): Social Network Analysis: A Handbook. Sage, London.

SCOTT, N., COOPER, CH. y BAGGIO, R. (2007): «Use of Network Analysis in Tourism Research», Advances in Tourism Marketing Conference, Valencia, Spain, 10-12 September.

SCOTT, N., COOPER, CH. y BAGGIO, R. (2008): «Destination Networks. Four Australian Cases», Annals of Tourism Research, vol. 55 n 1, pp. 169-188.

SCOTT, N., BAGGIO, R. y COOPER, CH. (2008a): Network Analysis and tourism. From Theory to Practice. Channel View, Clevedon.

SCOTT, N., BAGGIO R. y COOPER, CH. (2008b): «Technological Tourism Networks and Network Simulation» en Scott, N., Baggio, R. y Cooper, CH. Network Analysis and tourism. From Theory to Practice. Channel View, Clevedon.

SCOTT, N., BAGGIO, R. y COOPER, CH. (2008c): «Complex Tourism Networks» en Scott, N., Baggio, R. y Cooper, CH. Network Analysis and tourism. From Theory to Practice. Channel View, Clevedon.

SELIN, S. y BEASON, K. (1991): «Interorganizational relations in tourism». Annals of Tourism Research, 18(4), 639-652.

SESSA, A. (1976): «The tourism policy». Annals of Tourism Research, 3(5): pp 234-247.

SHEEHAN, L., y RITCHIE, J.R.B. (2005): «Destination stakeholders: Exploring identity and salience». Annals of Tourism Research, 32(3), 711-734.

SHIS, H. (2006): «Network characteristics of drive tourism destinations: An application of network analysis in tourism», Tourism Management, vol. 27, pp. 1029-1039. 
STOKOWSKI, P.A. (1990): «Extending the social group model: Social network analysis in recreation research». Leisure Sciences, 12, 251-263.

STOKOWSKI, P.A. y LEE, R.G. (1991): «The influence of social network ties on recreation and leisure: An exploratory study». Journal of Leisure Research, 23, 95-113.

STOKOWSKI, P.A. (1992): «Social networks and tourist behavior». American Behavioral Scientist, 36(2), 212-221.

TIMOTHY, D. (1998): «Cooperative tourism planning in a developing destination». Journal of Sustainable Tourism, 6(1), 52-68.

TIMUR, S. (2012): «Sustainable Tourism Networks», e-Review of Tourism Research, Best en Think Tank X, n 23.

TOSUN, C. (1999): «Limits to community participation in the tourism development process in developing countries». Tourism Management, 21(6), 613-633.

URRY, J. (2003): «Social network, travel and talk». Britsh Journal of Sociology, vol. 54, $\mathrm{N}^{\circ} 2$, pp. 155-175.

WASSERMAN, S. y GALASKIEWICZ, J. (1994): Advances in Social Networks Analysis. Sage, Thousand Oaks.

WATTS, D.J. (2003): The Science of a Coonected Age. W.W. Norton y Company, Nueva York.

WELLMAN, B. y BERKOWITZ, S.D. (1988) (Eds.): Social Structure: A Network Approach. Cambridge University Press, Cambridge.

ZEHRER, A. y RAICH, F. (2010): «Applying a life cycle perspective to explain tourism network development». The Service Industries Journal, vol. 30, No 10, pp. 1.6831.705 . 